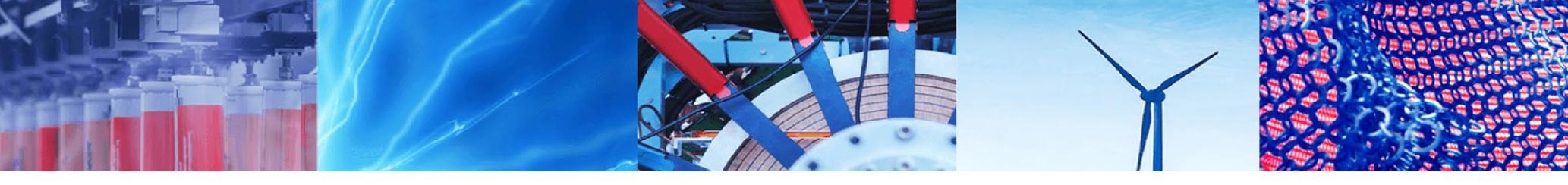

Research Article

\title{
Assessing the soil quality index as affected by two land use scenarios in Miandoab region
}

\author{
Nastaran Pouladi ${ }^{1}$ Ali Asghar Jafarzadeh ${ }^{1} \cdot$ Farzin Shahbazi $^{1} \cdot$ Mohammad Ali Ghorbani $^{2} \cdot$ Mogens H. Greve $^{3}$
}

Received: 26 July 2020 / Accepted: 7 October 2020 / Published online: 23 October 2020

(c) Springer Nature Switzerland AG 2020

\begin{abstract}
In this research, the physical, chemical and biological properties of 19 soil indicators using 80 samples $(0-25 \mathrm{~cm})$ were quantified to measure the soil quality index (SQI) in Miandoab region, Iran, across different land uses. These properties include aggregate stability (AS), bulk density (BD), soil moisture content $\left(\theta_{\mathrm{m}}\right)$, saturation percentage (SP), particle size fractions (clay, silt, sand), $\mathrm{pH}, \mathrm{EC}$, available $\mathrm{P}$ and $\mathrm{K}, \mathrm{OC}$, total $\mathrm{N}, \mathrm{C} / \mathrm{N}, \mathrm{CaCO}_{3}$, sequestration of organic carbon (SOC), $\mathrm{CEC}$, microbial respiration (MR) and microbial population (MP). Principal component analysis (PCA) was used as a dimension reduction method to separate farmlands and orchards as two different land uses. The linear SQI and nonlinear SQI were calculated, and the results showed a clear difference in SQI as affected by the aforementioned land uses. The specific contribution of each minimum data set also showed that soil OC, N, MR, MP, silt, $\mathrm{CaCO}_{3}, \mathrm{AS}$ and $\mathrm{BD}$ had the highest importance to SQI. The linear SQI value was more significantly affected by the physical properties than the chemical and biological ones. It varies from the maximum value of $35.17 \%$ in the farmland to $37.74 \%$ in the orchard. On the other hand, the nonlinear SQI showed the highest contribution of biological SQI in the farmland (73.94\%) followed by the orchard (64.15\%). Finally, both linear and nonlinear equations may be acceptable for assessing SQI using the aforementioned soil properties. Furthermore, it is the biological properties that have the main role in terms of evaluating the effect of land use conversion on soil quality.
\end{abstract}

Keywords Farmland· Orchard · Principal component analysis

\section{Introduction}

According to the United States Department of Agriculture Natural Resources Conservation Service, "Soil quality is the capacity of a specific kind of soil to function, within natural or managed ecosystem boundaries, to sustain plant and animal productivity, maintain or enhance water and air quality, and support human health and habitation" [1]. This capacity is an inherent characteristic [2], which varies from one to another soil and consists of physical, chemical and biological properties, namely the soil quality indicators that reflect the soil condition [3]. The dynamic soil properties such as soil organic matter and microbial attributes are sensitive to agricultural activities and land use changes [4], and land use alterations can have an adverse impact on soil function [5]. In addition, soil properties are often interdependent but under various agricultural and management activities may affect the soil quality and productivity and respond differently, so the interpretation of their effects under different management will be confusing [6].

Notwithstanding the interpretation of soil quality based on the individual microbial properties is a challenge, and soil quality relies on soil nutrients that can be affected by

\footnotetext{
$\triangle$ Nastaran Pouladi, Nastaran.pouladi@gmail.com | 'Soil Science Department, Faculty of Agriculture, University of Tabriz, Tabriz, Iran. ${ }^{2}$ Water Engineering Department, Faculty of Agriculture, University of Tabriz, Tabriz, Iran. ${ }^{3}$ Department of Agroecology, Aarhus University, Blichers Allé 20, 8830 Tjele, Denmark.
} 
land use changes and management activities [7]. They can inherently be the potential indicators of the soil quality, because of their higher sensitivity compared to the physical and chemical properties [8]. Therefore, based on different environmental conditions there are several tools and techniques which are needed for a competent assessment of these changes based on the concept of soil quality [9]. Since the definition of soil quality by several properties is complicated, the necessity of individual index is clear. But, it should be mentioned that the unified soil quality indices derived by different soil properties can be a better representative index for soil quality than an individual index [10].

The high value of soil quality indices shows that soil quality has a better function toward different aspects such as long-term productivity [2]. Based on Doran and Parkin [11] reports, the properties with information about soil function will make the minimum data set (MDS) as well as results favorable soil quality indices. The MDS was achieved using mathematical techniques and scoring functions (linear and nonlinear). Principal component analysis (PCA) is one of the most commonly used techniques for selecting MDS which reduces the data redundancy and makes a facility to select the indicators by classifying the soil properties into different principal components (PC) $[12,13]$. Based on the importance of the SQI assessment in both farmland and orchard, it is possible to have clear discrimination between mentioned land uses to see how the land use conversion can affect the soil quality. So our hypothesis was that the SQI is a proper tool to evaluate the effect of different land use on soil quality. Therefore, the main objectives of this research work were to (i) identify the minimum data set (MDS) including the most important soil quality indicators for soil quality assessment, (ii) develop the linear and nonlinear scoring function for different land uses and (iii) investigate the effect of farmland and orchard land uses on the soil quality.

To our awareness, this research is the first report which is done in the vicinity of the Urmia lake area regarding the assessment of the SQI by physical, chemical and biological properties in different land uses, where the land use change in this area is growing fast and the lake is in the danger of being dried because of the mismanagement and inappropriate agriculture activities, the importance of this kind of research seems more necessary.

\section{Materials and methods}

\subsection{Study area}

The study area with farmland and orchard was located in Miandoab region, West Azerbaijan province of Iran. It lies between a latitude of $36^{\circ} 52^{\prime}$ to $37^{\circ} 02^{\prime} \mathrm{N}$ and a longitude of $46^{\circ} 00^{\prime}$ to $46^{\circ} 14^{\prime} \mathrm{E}$ covering about 7000 ha (Fig. 1). The synoptic station of Miandoab climatic data showed an average annual, maximum and minimum temperatures of $12.8,19.9$ and $7.5^{\circ} \mathrm{C}$, respectively. Also, the average annual rainfall and evapotranspiration were recorded as 272.3-733.3 mm, respectively. The area has a Mesic soil temperature regime and Aridic moisture [14].

\subsection{Soil data}

For determining the location of the sampling points, grid surveying was carried out based on the size of the lands and aim of the study which is a commonly used approach [15]. The entire study area covers with a grid of $1000 \times 700 \mathrm{~m}$, and in total, 80 samples $(0-25 \mathrm{~cm})$ were collected, transported to the laboratory and after air drying were prepared with passing through a $2 \mathrm{~mm}$ sieve for physical and chemical analysis. Field moist soil samples were also maintained at $4{ }^{\circ} \mathrm{C}$ and prepared for microbial analysis.

All the measured properties as soil quality indicators were selected based on [16] list. Soil physical properties such as aggregate stability (AS) [17], bulk density (BD) [18], soil moisture content $\left(\theta_{m}\right)$ [19], saturation percentage (SP) [20] and texture [21] with chemical properties of soil reaction $(\mathrm{pH})$ [22], electrical conductivity (EC) [23], available phosphor (P) [24], absorbing potassium (K) [25], organic carbon $(\mathrm{OC})$ [26], total nitrogen $(\mathrm{N})$ [27], the ratio of carbon to nitrogen $(\mathrm{C} / \mathrm{N})$, calcium carbonate equivalent $\left(\mathrm{CaCO}_{3}\right)$ [28], sequestration of organic carbon (SOC) and cation exchange capacity (CEC) [29] were determined. Also, microbial respiration (MR) [30], and microbial population (MP) [31] were calculated as microbial properties in this research.

\subsection{Scoring the soil quality index}

Soil quality index (SQI) was computed through the three steps: (i) selecting sensitive indicators for an MDS, (ii) scoring the MDS indicators and (iii) unifying the scores into an index $[32,33]$. For the matter, a total of 19 soil physical, chemical and biological properties were measured based on their sensitivity and ability for expressing the complexity and functionality of soils [34].

The principal component analysis (PCA) was carried out using the SPSS software v20.0 for determining the MDS indicators. This way causes to select the most important indicators as well as to reduce the dimension of the data set without losing any information [35]. Based on the eigenvalue of the $\mathrm{PC}$, the indicator with eigenvalue $>1$ was accounted as the best representative indicator for the soil quality which can explain at least $5 \%$ of 

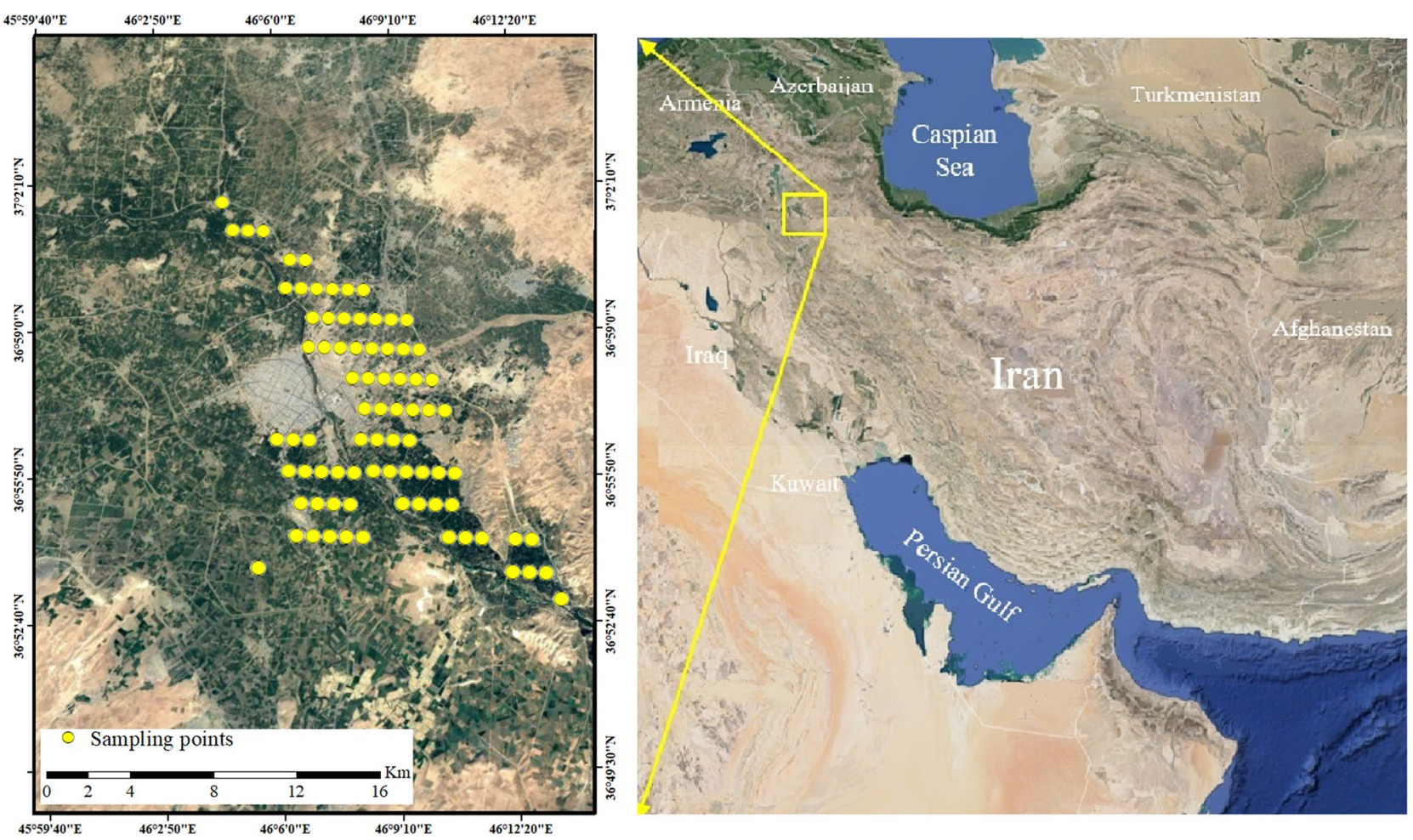

Fig. 1 The location of the study area in Miandoab region, northwest of Iran

the data variation. In other words, the highly weighted indicators with $>0.50$ factor loading value were considered as soil quality indicators [36]. Whenever there was more than one indicator in each factor, the multivariate correlation coefficient would decide if the indicator could remain in the factor or it should be omitted from the MDS; indeed, it will decrease the redundancy. In a case that indicator was highly weighted with no correlation between PC and soil properties, each accounted as an important one and remained in the MDS [36]. After selecting the MDS, the linear and nonlinear scoring functions were applied for scoring them between 0 and 1 because the aforementioned soil indicators consist of different units [6]. Based on the effects of indicators on the soil quality, they were scored as "more is better" for one with a positive effect on the soil quality, "less is better" for one with negative effects and "optimum" for one which can have a positive effect on increasing part and negative effect on decreasing part [37]. In this study, the bulk density was scored as "less is better", silt and $\mathrm{CaCO}_{3}$ was scored as "optimum" and the rest of the indicators maintained in the MDS were scored as "more is better." The following linear scoring functions (Eqs. 1 and 2) were used as "more is better" and "less is better," respectively.
$L=\frac{x}{x_{\max }}$

$L=\frac{x_{\min }}{x}$

where $L$ is the linear score varying from 0 to $1, x$ is the value of soil property, and $x_{\max }$ and $x_{\min }$ are the maximum and minimum values of each observed soil property [38]. The nonlinear scoring function was also used in the sigmoidaltype curve (Eq. 3).

$\mathrm{NL}=\frac{a}{\left(1+\left(\frac{x}{x_{0}}\right)^{b}\right)}$

where $N L$ is the nonlinear score of each indicator (between 0 to 1 ), a stands for the maximum value (in this study $a=1$ ) reached by the function, $x$ is the value of the selected indicator, $x_{0}$ is the mean value of each indicator, and $b$ is the slope of the equation which was set as -2.5 for "more is better" and 2.5 for "less is better" functions [38].

Notwithstanding the linear scoring is easier to be calculated [39], the nonlinear scoring technique can determine the function better than a linear one. Moreover, the 
nonlinear technique needs pre-knowledge and skill for interpreting the behavior of each indicator in the system. However, in most cases, both linear and nonlinear functions show almost similar results [36]. The last step for the soil quality assessment was to combine the selected indicators into a single index using Eq. 4.

$\mathrm{SQI}=\sum_{i=1}^{n} \mathrm{~W}_{i} \mathrm{~S}_{i}$

where $W i$ is the weighting factor of each indicator derived by factor analysis and $S_{i}$ is the linear and nonlinear scores calculated via Eqs. 1-3 [40]. In final, according to the value of SQI, the effects of land use on the soil function have been evaluated. It assumes that the higher SQI value relates to the better soil quality [6].

\subsection{Statistical analyses}

The data were checked for normality distribution. For this, the paired t-test method applied at the $P<0.05$ significance level by SPSS software v20.0. Then, the significance level of SQI was tested based on the relative importance of scoring methods. Finally, the ordinary kriging method was applied to interpolate the value of unsampled points as it minimized the error variance [41]. Before mapping, spherical, Gaussian, stable and exponential models were tested for experimental semivariogram calculation and the stable model was chosen based on the lowest RMSE and highest
$R^{2}$. The maps of SQI were created based on the linear and nonlinear scoring functions by ArcGIS software v10.2.

\section{Results and discussion}

\subsection{Soil analyses}

Table 1 shows the statistical characteristics of the measured properties of the 80 samples in the study; the samples exhibited a large variation in most of the soil properties. The normal distribution was tested based on the Kolmogorov-Smirnov method and the value of the kurtosis and skewness, and the non-normal parameters $(P<0.05)$ were normalized by the log transformation technique. This non-normality can be attributed to the changes in the sedimentation environments and the effect of pedogenic and hydrologic processes. On the other hand, agricultural management activities can also cause heterogenous distribution among the soil properties [42]. The $\mathrm{pH}$ coefficient of variation (CV\%) and standard deviation (Std. deviation) had the lowest and the second-lowest values, respectively, which can be related to the dominant parent material in the study area, whereas the high CV\% in N, $\mathrm{P}, \mathrm{K}$ and $\mathrm{EC}$ indicated the strong spatial variation of their content in the study area. These strong variations may be due to the variations in land use, soil types and the effect of management factors such as applying fertilizer in the field, topographic changes and the drainage condition in the study area (Table 1).
Table 1 Statistical characteristics of all data set

\begin{tabular}{|c|c|c|c|c|c|c|c|}
\hline Variable & Minimum & Maximum & Mean & Std. deviation & $\mathrm{CV} \%$ & Kurtosis & Skewness \\
\hline $\mathrm{pH}$ & 7.09 & 8.73 & 7.92 & 0.28 & 3.59 & -0.17 & 0.93 \\
\hline $\mathrm{EC}\left(\mathrm{dS} \cdot \mathrm{m}^{-1}\right)$ & 0.66 & 11.93 & 2.63 & 2.48 & 94.25 & 2.34 & 5.55 \\
\hline$P\left(\mathrm{mg} \cdot \mathrm{kg}^{-1}\right)$ & 0.44 & 41.50 & 5.85 & 6.39 & 109.11 & 3.23 & 13.23 \\
\hline $\mathrm{K}\left(\mathrm{mg} \cdot \mathrm{kg}^{-1}\right)$ & 5.00 & 872.00 & 187.30 & 179.70 & 95.94 & 2.07 & 4.19 \\
\hline AS (\%) & 2.62 & 19.53 & 11.39 & 3.56 & 31.33 & -0.12 & -0.23 \\
\hline $\mathrm{BD}\left(\mathrm{gr} \mathrm{cm}^{-3}\right)$ & 1.08 & 1.78 & 1.43 & 0.40 & 23.10 & 0.62 & -0.26 \\
\hline$\theta \mathrm{m}(\%)$ & 0.51 & 1.55 & 1.05 & 0.08 & 8.45 & -0.77 & 28.66 \\
\hline SP (\%) & 31.30 & 91.77 & 54.98 & 11.63 & 21.16 & 0.44 & 0.92 \\
\hline Clay (\%) & 7.27 & 44.97 & 23.57 & 9.68 & 41.06 & 0.23 & -0.85 \\
\hline Silt (\%) & 5.00 & 66.00 & 39.12 & 12.72 & 32.52 & -0.41 & -0.38 \\
\hline Sand (\%) & 5.00 & 81.00 & 37.30 & 17.29 & 46.35 & 0.58 & -0.27 \\
\hline OC (\%) & 0.04 & 3.16 & 1.79 & 0.68 & 38.42 & -0.98 & 0.29 \\
\hline N (\%) & 0.00 & 0.55 & 0.13 & 0.08 & 62.51 & 1.98 & 6.95 \\
\hline $\mathrm{C} / \mathrm{N}$ & 0.03 & 5.18 & 1.64 & 0.94 & 0.57 & 0.94 & 1.21 \\
\hline $\mathrm{CaCO}_{3}(\%)$ & 2.25 & 12.50 & 6.45 & 3.76 & 58.29 & 0.88 & -0.98 \\
\hline SOC (ton ha-1) & 1.68 & 179.69 & 95.23 & 42.86 & 45.00 & -0.31 & -0.31 \\
\hline CEC (meq.100 $\mathrm{gr}^{-1}$ ) & 4.17 & 31.65 & 16.42 & 6.13 & 37.31 & 0.48 & -0.11 \\
\hline $\mathrm{MR}\left(\mathrm{mg} \mathrm{kg}^{-1}\right)$ & 1.67 & 9.28 & 4.39 & 1.97 & 44.86 & 0.65 & -0.47 \\
\hline $\mathrm{MP}\left(10^{-5} \mathrm{gr}^{-1}\right)$ & 139.32 & 274.93 & 187.88 & 35.11 & 18.68 & 0.65 & -0.47 \\
\hline
\end{tabular}




\subsection{Selecting indicators}

Different properties cause changes in the soil condition under different land uses. The factor analysis tries to select the most important ones with a high variation for getting more information about soil and assessing the land use effect on soil quality, and it also prevents some of the time-consuming and high-cost activities in large-scale area where they have the same ecosystem and condition [43]. Communalities define the contribution of variance in each soil property which are illustrated by the PCA; in other words, high communalities in the properties show the high value of variance by PCA [44].

The selected 19 soil profiles properties, relevant to the soil quality, were accounted for the PCA. The results are summarized in Table 2. Seven factors revealed the eigenvalues greater than 1 , which indicate the soil quality and its diversity. They explain more than $5 \%$ of the data variation and jointly about $79 \%$ of the total variance. The first factor shows $13.1 \%$ of the total variation, while factors 2 to 7 represent $12.63 \%, 11.91 \%, 11.83 \%, 11.56 \%, 10.85 \%$ and $7.15 \%$ of the variations, respectively (Table 2 ). In the first factor, the high loading values belong to the chemical properties of SOC (0.881) followed by OC $(0.855)$ and
$\mathrm{C} / \mathrm{N}(0.615)$. Carbon was reported as a key property for SQI evaluation, which can have different effects on the soil chemical, physical and biological properties $[45,46]$. The second factor was associated with chemical and physical properties including $\mathrm{N}$ and SP with the highest loading value of 0.886 and 0.758 , respectively. Both MR and MP as two biological properties are recorded with the most highly weighted ones in the third factor. Silt with a positive high loading value (0.882) and sand with negative high loading value $(-0.864)$ are identified as two important properties in the fourth factor. The most important properties in factor 5 are relevant to chemical properties and fertility and include $\mathrm{CaCO}_{3}(0.802)$, CEC (0.740) and $\mathrm{K}(0.711)$. Finally, the highly weighted properties in factor 6 are AS (0.865) and clay (0.716), while EC (0.689) is distinguished in factor 7 (see Table 2). The commonality values for all variables are recorded more than 0.50 , which explains the high variance of soil properties and the expansion of factor analysis. For an instant, four soil properties of sand, SOC, MR and MP could explain more than $90 \%$ of the variance in this work.

The vector loading plot (Fig. 2) shows the effects of each variable on the components. The loading ranged from -1 to 1 . If it is closer to -1 or 1 , the effect of the

Table 2 Results of principal component analysis (PCA) of soil quality indicators

\begin{tabular}{|c|c|c|c|c|c|c|c|c|}
\hline Soil properties & Factor 1 & Factor 2 & Factor 3 & Factor 4 & Factor 5 & Factor 6 & Factor 7 & Commonality $^{a}$ \\
\hline $\mathrm{pH}$ & 0.25 & -0.29 & 0.38 & 0.49 & 0.01 & -0.17 & 0.00 & 0.58 \\
\hline $\mathrm{EC}\left(\mathrm{dS} \cdot \mathrm{m}^{-1}\right)$ & -0.18 & 0.29 & 0.07 & 0.05 & -0.14 & -0.04 & 0.68 & 0.62 \\
\hline $\mathrm{P}\left(\mathrm{mg} \cdot \mathrm{kg}^{-1}\right)$ & -0.08 & 0.58 & 0.01 & -0.01 & 0.55 & -0.36 & 0.10 & 0.80 \\
\hline $\mathrm{K}\left(\mathrm{mg} \cdot \mathrm{kg}^{-1}\right)$ & -0.41 & -0.05 & 0.03 & -0.05 & 0.71 & 0.01 & 0.09 & 0.69 \\
\hline AS (\%) & -0.10 & 0.19 & -0.19 & -0.08 & 0.03 & $\underline{0.86}$ & -0.01 & 0.84 \\
\hline $\mathrm{BD}\left(\mathrm{gr} \mathrm{cm}^{-3}\right)$ & 0.33 & -0.21 & 0.09 & -0.03 & -0.03 & 0.10 & $\underline{0.76}$ & 0.76 \\
\hline$\theta_{\mathrm{m}}(\%)$ & -0.04 & 0.20 & 0.41 & 0.21 & -0.14 & 0.42 & -0.23 & 0.51 \\
\hline SP (\%) & 0.09 & 0.75 & -0.05 & 0.44 & 0.05 & 0.23 & 0.04 & 0.85 \\
\hline Clay (\%) & 0.10 & 0.08 & -0.05 & 0.38 & 0.14 & 0.71 & 0.16 & 0.73 \\
\hline Silt (\%) & 0.05 & 0.17 & 0.00 & $\underline{0.88}$ & 0.00 & -0.01 & -0.04 & 0.81 \\
\hline Sand (\%) & -0.09 & -0.17 & 0.02 & -0.86 & -0.08 & -0.39 & -0.06 & 0.95 \\
\hline OC (\%) & 0.87 & 0.18 & 0.13 & 0.16 & -0.21 & 0.02 & -0.13 & 0.90 \\
\hline $\mathrm{N}(\%)$ & 0.06 & $\underline{0.88}$ & -0.06 & 0.07 & -0.07 & 0.21 & 0.00 & 0.85 \\
\hline $\mathrm{C} / \mathrm{N}$ & 0.61 & -0.51 & 0.19 & 0.00 & -0.17 & -0.27 & 0.00 & 0.78 \\
\hline $\mathrm{CaCO}_{3}(\%)$ & -0.24 & -0.03 & -0.07 & 0.04 & $\underline{0.80}$ & -0.02 & -0.11 & 0.72 \\
\hline SOC (ton.ha ${ }^{-1}$ ) & $\underline{0.88}$ & -0.00 & 0.17 & 0.11 & -0.17 & 0.06 & 0.29 & 0.93 \\
\hline CEC (meq.100gr ${ }^{-1}$ ) & 0.13 & 0.10 & 0.15 & 0.14 & 0.74 & 0.30 & -0.22 & 0.76 \\
\hline $\mathrm{MR}\left(\mathrm{mg} \cdot \mathrm{kg}^{-1}\right)$ & 0.14 & -0.06 & $\underline{0.94}$ & -0.00 & 0.04 & -0.09 & 0.09 & 0.92 \\
\hline $\operatorname{MP}\left(10^{-5} \cdot \mathrm{gr}^{-1}\right)$ & 0.14 & -0.06 & $\underline{0.94}$ & -0.00 & 0.04 & -0.09 & 0.09 & 0.92 \\
\hline Eigenvalue & 3.90 & 3.66 & 2.31 & 1.54 & 1.32 & 1.19 & 1.05 & 15.00 \\
\hline Variance (\%) & 13.01 & 12.63 & 11.91 & 11.83 & 11.56 & 10.85 & 7.15 & 78.97 \\
\hline Cumulative variance (\%) & 13.01 & 25.64 & 37.56 & 49.40 & 60.97 & 71.82 & 78.97 & \\
\hline
\end{tabular}

Bold loading values $(>0.50)$ indicate the highly weighted factors

Bold-underlined values were the factors included in the MDS 


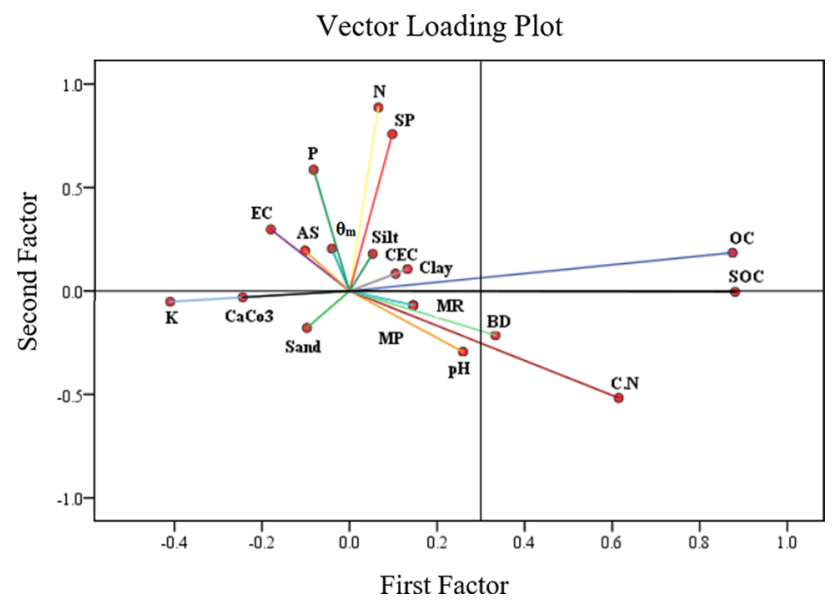

Fig. 2 A vector loading plot of the first and second factors in farmland and orchard land uses

variable on the component will be larger until it is close to 0 , the variable has a weak influence on the component [47]. The results show that $\mathrm{SOC}$ in factor 1 and $\mathrm{N}$ in factor 2 have maximum influence among the tested variables, so they should be considered as the main indicators in soil quality evaluation under farmland and orchard land uses.

Table 3 represents the correlation of the measured soil properties. Under the first factor, SOC, OC and $C / N$ are all significantly correlated $(P<0.01)$ with each other, but only the SOC with the highest loading $(0.881)$ is selected in the MDS. This shows that any changes in the SOC content will affect the other soil properties, which are significantly correlated. Therefore, if there are more than one highly correlated variable, one will remain in MDS and the rest will be omitted [48]. Nitrogen and SP are also highly correlated $(r=0.70, P<0.01)$ in factor 2 , and $N$ is selected for MDS with 0.886 loading value. MR and MP with more than $11 \%$ of the total variation were the most important properties in factor 3 which are highly correlated $(r=1.0, P<0.01)$, and both are kept in MDS; these two properties can replace each other as a soil quality indicator when one of them is not measured. Under factor 4 , silt and sand are highly correlated $(r=-0.83)$ with 0.882 and -0.864 loading value, respectively, but the silt is kept in MDS. Although the $\mathrm{CaCO}_{3}(0.802), \mathrm{CEC}$ (0.74), $\mathrm{K}(0.711)$ and $\mathrm{P}(0.553)$ in factor 5 are all significantly correlated, the $\mathrm{CaCO}_{3}$ due to its high loading value remained in MDS. Under factor 6 , the AS and clay with 0.865 and 0.716 loading value, respectively, are significantly correlated $(r=0.53, P<0.01)$ and AS is kept in MDS. In factor 7, BD (0.768) and EC (0.689) do not have high correlation $(r=0.18, P<0.01)$ and $\mathrm{BD}$ is considered as an indicator in MDS. Overall, the indicators retained in MDS include $\mathrm{SOC}, \mathrm{N}, \mathrm{MR}, \mathrm{MP}$, silt, $\mathrm{CaCO}_{3}, \mathrm{AS}$ and $\mathrm{BD}$ which are considered as the most important variables in creating the SQI under different land uses.

\subsection{The scores of indicators}

The linear and nonlinear functions were applied for scoring the MDS indicators. They were classified into three groups: 1) SOC, N, AS, MR and MP indicators as "more is better" functions due to their positive influence on soil quality (i.e., management purposes and crop productivity); 2) $B D$ as "less is better" function demonstrates a negative effect on the soil quality [37]; and 3) other soil properties of silt and $\mathrm{CaCO}_{3}$ as "optimum" function due to both positive and negative effects on soil quality. The summary of criteria used by the scoring functions for all MDS indicators entire of the study area is represented in Table 4.

\subsection{Soil quality index}

The SQI was calculated using the weighting factor of each indicator derived by factor analysis and the linear as well as nonlinear scores (Fig. 3). The results showed that the SQI values in farmland were greater than the orchard, which may be resulted by the presence of plant residues on the soil surface. Besides, in addition, fertilization of farmland increases soil nutrients of SOC, $\mathrm{N}$ and $\mathrm{P}$ due to an increase in organic matter input [13], so they affect the microbial activity, organic carbon content and other soil properties [49]. In this study, the values of SQI using the linear function are also greater than the nonlinear function in both land uses (Fig. 3).

Based on the contribution of each MDS to SQI (Fig. 4), the MP contributes with the highest score using both linear $(17.84 \%$ in the farmland and $16.93 \%$ in the orchard) and nonlinear functions $(18.16 \%$ and $17.33 \%$ in the farmland and orchard, respectively). It was found as the highest loading value in factor analysis (Table 2). The second highest contributor to linear SQI is related to SOC and silt in farmland and orchard, respectively. They had a high loading value $(13.01 \%)$ and variance $(11.83 \%)$ in the factor analysis (Table 2). The high contribution of SOC in farmland SQI shows the importance of SOC as an important indicator, which can be explained by the low amount of SOC in the soil that can have an effect on soil functions and processes such as nutrient cycling and microorganism. In addition, obtained result by Yao et al. [50] with a similar climate condition and low amount of SOC reported the same properties as the main indicator, which is influenced by soil management, land use and the lower contribution of other properties in SQI, plus it can be also related to less correlation of these properties. Furthermore, recovery of the crop biomass to the farmland than orchard can improve the soil labile carbon sequestration [13]. In 


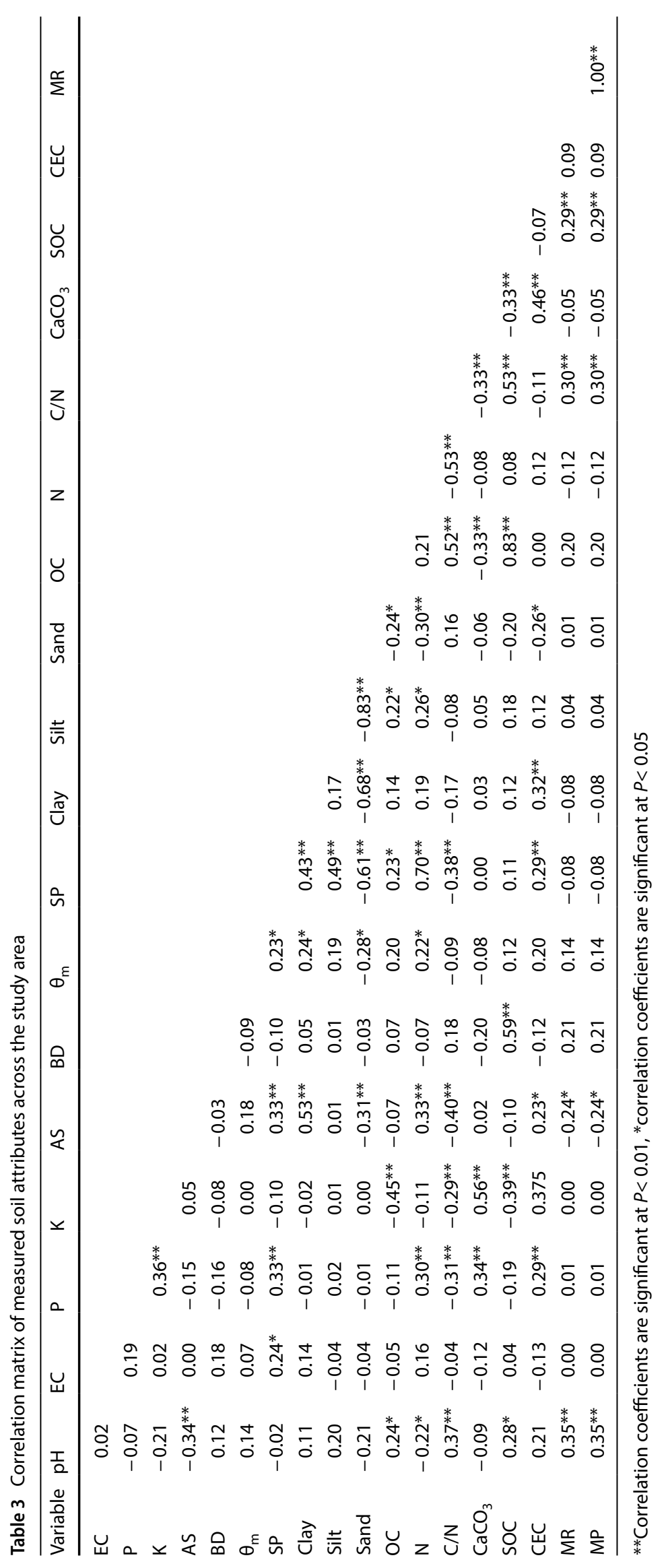


Table 4 Summary of average and range values normalized linear and nonlinear equations of the scoring functions for all MDS

\begin{tabular}{|c|c|c|c|c|c|c|c|c|}
\hline & SOC & $\mathrm{N}$ & MR & MP & Silt & $\mathrm{CaCO}_{3}$ & AS & $\mathrm{BD}$ \\
\hline Minimum & 1.68 & 0.01 & 5.79 & 139.31 & 5 & 2.25 & 2.62 & 1.08 \\
\hline $\begin{array}{l}\text { Maximum } \\
\left(x_{\max }\right)\end{array}$ & 179.68 & 0.54 & 32.23 & 274.92 & 66 & 12.5 & 19.53 & 2.78 \\
\hline $\begin{array}{l}\text { Average } \\
\left(x_{0}\right)\end{array}$ & 95.23 & 0.13 & 15.26 & 187.88 & 39.12 & 6.45 & 11.39 & 1.75 \\
\hline $\begin{array}{l}\text { Curve type } \\
\text { (scoring } \\
\text { function) }\end{array}$ & More is better & More is better & More is better & More is better & Optimum & Optimum & More is better & Less is better \\
\hline $\begin{array}{l}\text { Weighting } \\
\text { factor }^{\text {a }}\end{array}$ & 0.13 & 0.12 & 0.11 & 0.11 & 0.11 & 0.11 & 0.10 & 0.07 \\
\hline $\begin{array}{r}\text { Slope (b } \\
\text { value) }\end{array}$ & -2.5 & -2.5 & -2.5 & -2.5 & -2.5 & -2.5 & -2.5 & 2.5 \\
\hline $\begin{array}{l}\text { Normal- } \\
\text { ized } \\
\text { linear } \\
\text { equa- } \\
\text { tion }\end{array}$ & $0.13(x / 179.68)$ & $0.12(x / 0.54)$ & $0.11(x / 32.23)$ & $0.11(x / 274.92)$ & $0.11(x / 66)$ & $0.11(x / 12.5)$ & $0.10(x / 19.53)$ & $0.07(x / 2.78)$ \\
\hline $\begin{array}{l}\text { Normal- } \\
\text { ized }\end{array}$ & $0.13 \times 1 /$ & $0.12 \times 1 /$ & $0.11 \times 1 /$ & $0.11 \times 1 /$ & $0.11 \times 1 /$ & $0.11 \times 1 /$ & $0.10 \times 1 /$ & $0.07 \times 1 /$ \\
\hline $\begin{array}{l}\text { Nonlinear } \\
\text { equa- } \\
\text { tion }\end{array}$ & $\left(1+(x / 95.23)^{-2.5}\right)$ & $\left(1+(x / 0.13)^{-2.5}\right)$ & $\left(1+(x / 15.26)^{-2.5}\right)$ & $\left(1+(x / 187.88)^{-2.5}\right)$ & $\left(1+(x / 39.12)^{-2.5}\right)$ & $\left(1+(x / 6.45)^{-2.5}\right)$ & $\left(1+(x / 11.39)^{-2.5}\right)$ & $\left(1+(x / 1.75)^{2.5}\right)$ \\
\hline
\end{tabular}

${ }^{a}$ Derived from factor analysis (please see Table 2)

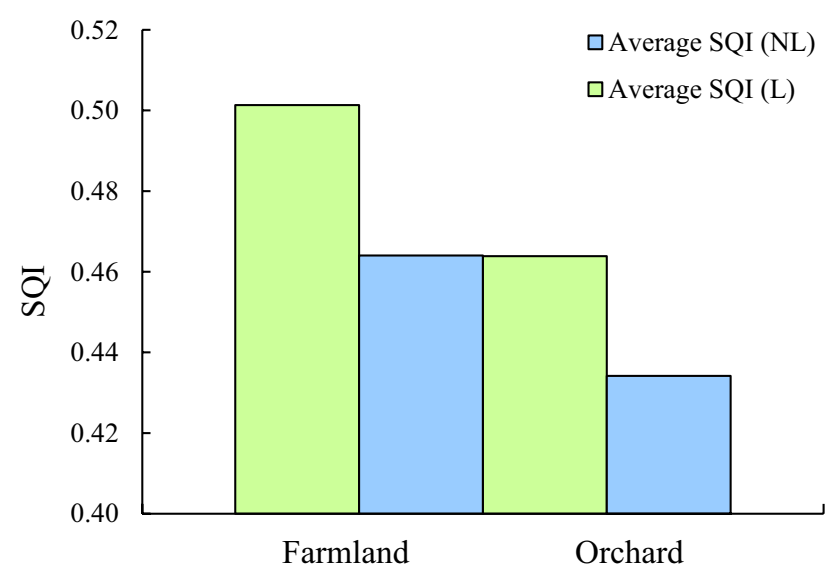

Fig. 3 The average linear and nonlinear SQI in farmland and orchard nonlinear SQI, the MR and $\mathrm{N}$ have the highest contribution in farmland and orchard, respectively, following MP. These results represent the effect of the weighting factor in factor analysis.

The contributions of physical, chemical and biological indicators were affected by two land use scenarios are illustrated in Fig. 5. Applying the linear function showed that soil physical properties had a higher contribution compared with the chemical and biological ones with the $35.17 \%$ value in farmland and $38.74 \%$ in the orchard. But the application of nonlinear function revealed that the biological properties had the highest value in both land uses $(73.94 \%$ and $64.15 \%$ for farmland and orchard, respectively). The factor analysis had also shown the same
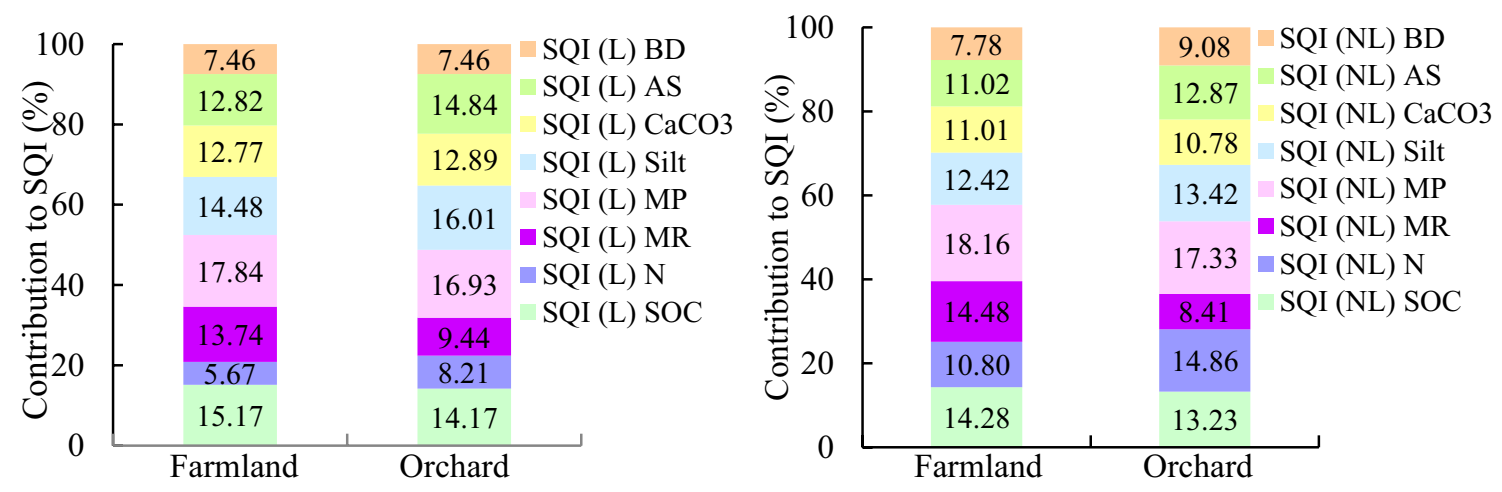

Fig. 4 The contribution of the MDS indicators to the SQI using linear and nonlinear scoring functions for both farmland and orchard land uses 

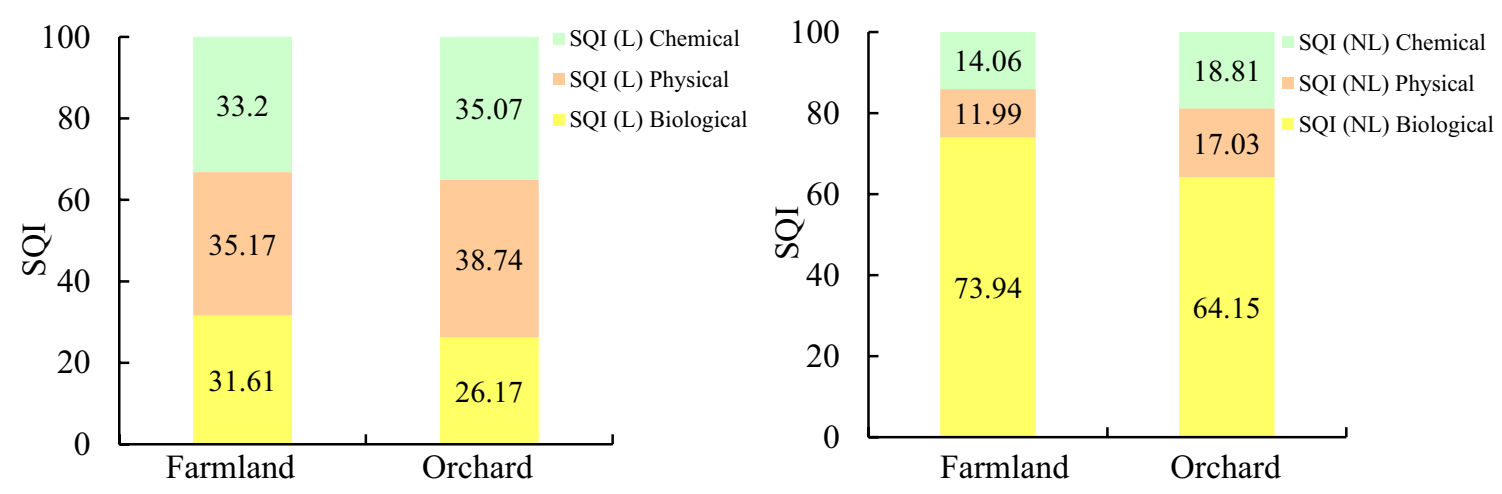

Fig. 5 The contribution of the chemical, physical and biological indicators to the SQI by linear and nonlinear scoring functions in farmland and orchard

results in which the biological indicators (MP and MR) had a high loading value and variance (Table 2 ).

Additionally, the contribution of biological indicators in farmland was larger than the orchard, using both linear and nonlinear functions (Fig. 5), which may be caused by more agricultural activities such as tillage in farmland. These activities can easily alter the soil condition favored to microbial growth by providing more substrate. The biological properties are sensitive to any management practice or any other agricultural activity [49]. On the contrary, the physical and chemical properties need longterm and intensive activity to be changed, so their impact on soil quality is less than the biological properties [51]. Furthermore, the relationship between soil quality and different land uses is influenced by different factors like climate, soil type, crop varieties and other factors that are
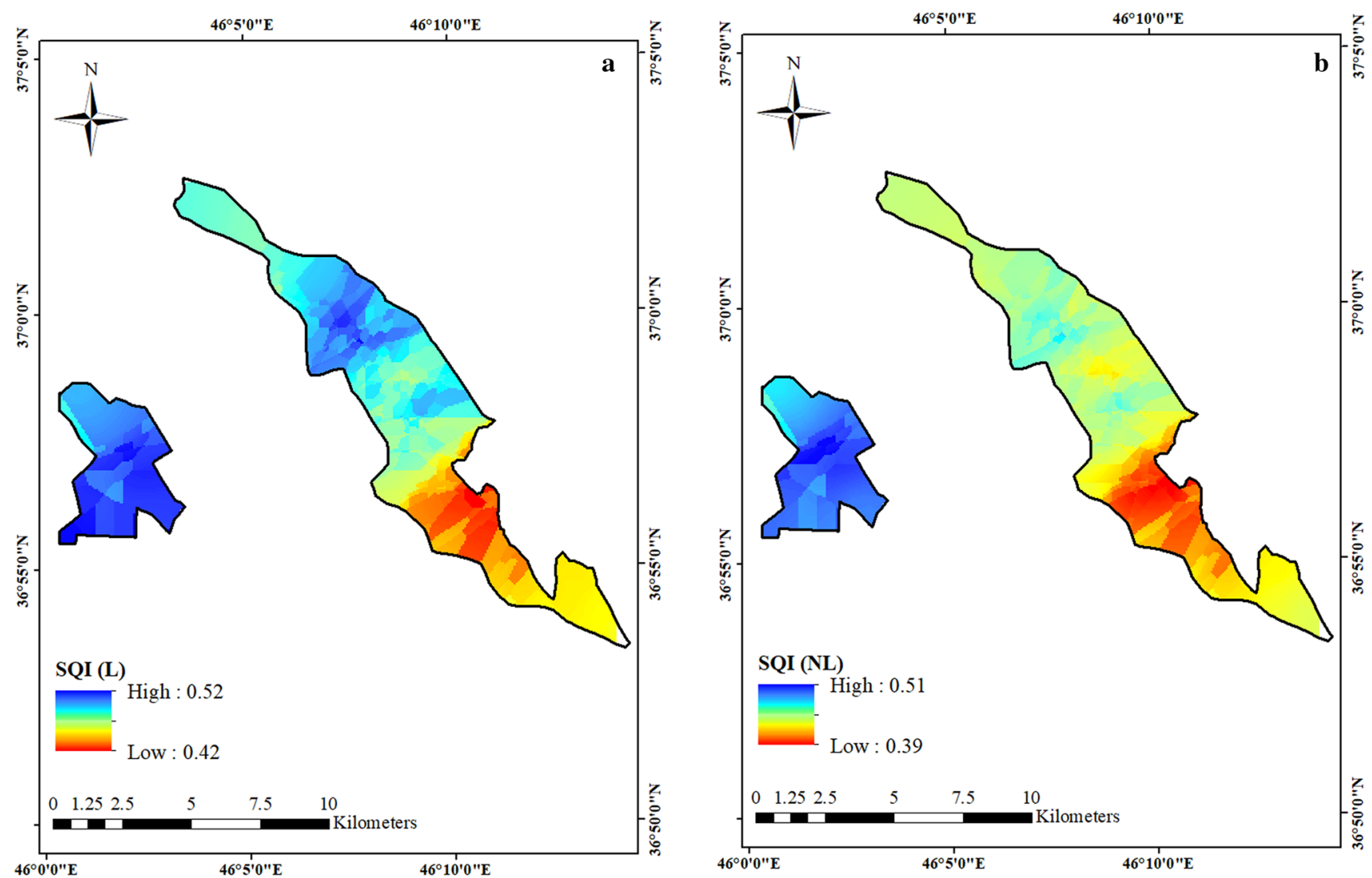

Fig. 6 The SQI maps by a linear and b nonlinear scoring functions in the study area 
not evaluated in this research [47]. Figure 6 represents the SQI maps by the linear and nonlinear scoring function in the study area and shows almost the same range of SQI in both linear and nonlinear scoring functions.

\section{Conclusions}

In this research work, the practical usage of the SQI assessment is reported to define the effect of land use conversion on soil quality. Therefore, some physical, chemical and biological properties of soil were quantified using 80 samples to measure the soil quality index (SQI) in the Miandoab region, Iran. The results represented that soil $\mathrm{SOC}, \mathrm{N}, \mathrm{MR}, \mathrm{MP}$, silt, $\mathrm{CaCO}_{3}$, AS and $\mathrm{BD}$ had a high contribution to SQI and SOC made the highest variation to SQI (13.01\%) followed by N (12.63\%) and MR and MP (11.91\%). The linear SQI values were more significantly affected by physical properties, while the nonlinear SQI showed the highest contribution of biological properties. Generally, the most sensitive indicators as affected by land use were the biological properties, which showed a high contribution to SQI in both linear and nonlinear functions. This confirms that agricultural activities like tillage have increased microbial activity and soil quality. In addition, there was no clear difference between linear and nonlinear equations to evaluate SQI. Furthermore, it should be considered in the future studies that although the SQI is a simple and flexible method, measured by different soil properties for monitoring the soil health, it is the biological properties that have the main role in terms of evaluating the effect of land use conversion on soil quality.

Acknowledegments We are grateful to the University of Tabriz for their kind encouragement and their financial support.

\section{Compliance with ethical standards}

Conflict of interest The authors declare that they have no conflict of interest.

\section{References}

1. Johnson $\mathrm{DL}, \mathrm{Amb}$ rose $\mathrm{SH}$, Bassett $\mathrm{TJ}$, Bowen $\mathrm{ML}$, Crummey DE, Isaacson JS, Johnson DN, Lamb P, Saul M, Winter-Nelson AE (1997) Meanings of environmental terms. J Environ Qual 26:581-589

2. Karlen DL, Gardner JC, Rosek MJ (1998) A soil quality framework for evaluating the impact of CRP. Prod Agric 11:56-60

3. de Paul Obade V, Lal R (2016) A standardized soil quality index for diverse field conditions. Sci Total Environ 541:424-434

4. Carter MR (2002) Soil quality for sustainable land management: organic matter and aggregation interactions that maintain soil functions. Agronomy 94:38-47
5. Emadi M, Baghernejad M, Memarian HR (2009) Effect of landuse change on soil fertility characteristics within water-stable aggregates of two cultivated soils in northern Iran. Land Use Policy 26:452-457

6. Raiesi F (2017) A minimum data set and soil quality index to quantify the effect of land use conversion on soil quality and degradation in native rangelands of upland arid and semiarid regions. Ecol Ind 75:307-320

7. Tiwari KR, Sitaula BK, Borresen T, Bajracharya RM (2006) An assessment of soil quality in Pokhare Khola watershed of the Middle Mountains in Nepal. J Food Agric Environ 4:276-283

8. de Castro A, Lopes A, Gomes de Sousa DM, Chaer GM, dos Reis B, Junior F, Goedert WJ, de Carvalho Mendes I (2013) Interpretation of microbial soil indicators as a function of crop yield and organic carbon. Soil Sci Soc Am J 77:461-472

9. Guo L, Sun Z, Ouyang Z, Han D, Li F (2017) A comparison of soil quality evaluation methods for Fluvisol along the lower Yellow River. CATENA 152:135-143

10. Armenise $E$, Redmile-Gordon MA, Stellacci AM, Ciccarese A, Rubino P (2013) Developing a soil quality index to compare soil fitness for agricultural use under different management in the Mediterranean environment. Soil Tillage Res 130:91-98

11. Doran JW, Parkin TB (1994) Defining and Assessing Soil Quality Defining Soil Quality for a Sustainable Environment. Social Society of America and American Society of Agronomy, Madison, pp 3-21

12. Andrews SS, Carroll CR (2001) Designing a soil quality assessment tool for sustainable agroecosystem management. Ecol Appl 11:1573-1585

13. Yu PJ, Liu SW, Zhang L, Li Q, Zhou DW (2018) Selecting the minimum data set and quantitative soil quality indexing of alkaline soils under different land uses in northeastern China. Sci Total Environ 616:564-571

14. Banaei MH (1998) Map of Iran soil moisture and heat regimes. Institute of Soil and Water Research Ministry of Agriculture, Tehran, Iran ((In Persian))

15. McKenzie N, Grundy M, Webster R, Ringrose-Voase A (2008) Guidelines for surveying soil and land resources. CSIRO Publishing, Clayton

16. USDA, 2006. Soil quality institute. Natural resources conservation service. https://soils.usda.gov/sqi/. Accessed 20 Feb (2006)

17. Lax A, Diaz E, Castillo V, Albaladejo J (1994) Reclamation of physical and chemical properties of a salinized soil by organic amendment. Arid Soil Res Rehabil 8:9-17

18. Black AL (1986) Bulk density. physical and mineralogical method. In: Klute A (ed) Methods of Soil Analysis Part 1. American Society of Agronomy Inc, Madison Wisconsin, pp 374-380

19. Baybordi M (2000) Soil physic. 10th edn. Tehran University, Iran

20. Hillel D (2004) Introduction to environmental soil physics Elsevier Academic Press

21. Gee GW, Or D (2002) Particle-size analysis. In: Dane JH, Topp GC (eds) Methods of soil analysis, Part 4 physical methods. American Society of Agronomy Inc, Madison Wisconsin, pp 255-293

22. Carter MR, Gregorich EG (2008) Soil sampling and methods of analysis, 2nd edn. CRC Press, Boca Raton

23. Rowell DL (1994) Soil Science: Method and application. Longman Group, London, p 345

24. Olsen SR, Sommer LE (1986) Phospharous. In: Page AL (ed) Methods of Soil Analysis, Part2 Agron Monoger, 9. ASA and SSSA, Madison, WI, pp 403-427

25. USDA (1954) Diagnosis and Improvement of Saline and Alkali Soils. USDA agric hand book Government print office, Washington, DC 
26. Walkey A, Black IA (1934) An examination of Degtjareff method for determining soil organic matter and a proposed modification of the chromic acid in soil analysis 1. Exp Soil sci soc Am 79:459-465

27. Burt R (2004) Soil survey laboratory methods manual. United States Department of Agriculture Natural Resources Conservation Service, USA, p 700

28. Loeppert RH, Suarez DL (1996) Carbonate. In: Sparks DL et al (eds) Methods of soil analysis, Part 3 chemical methods. Soils Science Society of America, Madison, pp 437-474

29. Bouwer H (1986) Intake rate: cylinder infiltratiometer. In: Klute A (ed) Methods of Soil Analysis, part1Physical and Mineralogical Methods. Wiley, Madison, pp 825-843

30. Anderson JPE (1982) Soil respiration. In: Miller RH, Keeney DR (eds) Methods of soil analysis Part2. Chemical and microbiological properties The American Society of Agronomy, Madison Wisconsin

31. Page AL, Miller RH, Keeney DR (1986) Methods of soil analysis Part2 2nd edn agron monogr 9. ASA and SSSA, Madison WI, $p$ 1159

32. Karlen DL, Stott DE (1994) A framework for evaluating physical and chemical indicators of soil quality. In: Doran JW, Coleman DC, Bezdicek DF, Stewart BA (eds) Defining soil quality for a sustainable environment. Soil Science Society of America, Madison WI , pp 53-72

33. Nabiollahi K, Golmohamadi F, Taghizadeh-Mehrjardi R, Kerry R, Davari M (2018) Assessing the effects of slope gradient and land use change on soil quality degradation through digital mapping of soil quality indices and soil loss rate. Geoderma 318:16-28

34. Moncada MP, Gabriels D, Cornelis WM (2014) Data-driven analysis of soil quality indicators using limited data. Geoderma 235-236:271-278

35. Rahmanipour F, Marzaioli R, Bahrami HA, Fereidouni Z, Bandarabadi SR (2014) Assessment of soil quality indices in agricultural lands of Qazvin Province. Iran Ecol Indic 40:19-26

36. Andrews SS, Karlen DL, Mitchell JP (2002) A comparison of soil quality indexing methods for vegetable production systems in Northern California. Agr Ecosyst Environ 90:25-45

37. Andrews SS, Karlen DL, Cambardella CA (2004) The soil management assessment framework: a quantitative soil quality evaluation method. Soil Sci Soc Am 68:1945-1962

38. Askari MS, Holden NM (2014) Indices for quantitative evaluation of soil quality under grassland management. Geoderma 230-231:131-142

39. Liebig MA, Varvel G, Doran JW (2001) A simple performancebased index for assessing multiple agroecosystem functions. Agronomy 93:313-318

40. Sharma KL, Mandal UK, Srinivas K, Vittal KPR, Mandal B, Grace JK, Ramesh V (2005) Long-term soil management effects on crop yields and soil quality in a dryland Alfisol. Soil Tillage Res 83:246-259

41. Yamamoto J (2005) Comparing ordinary kriging interpolation variance and indicator kriging conditional variance for assessing uncertainties at unsampled locations. In: Dessureault S, Ganguli R, Kecojevic V, Dwyer JG (eds) Application of computers and operations research in the mineral industry. Taylor and Francis, Balkema

42. Habibi M, Shirani H, Kamali A, Esfandiarpour Borujeni I (2015) Assessment of soil physical quality indicators using remote sensing and geostatistics in Baft area. Soil Manag Sustain Prod 5(1):159-172 ((In Persian))

43. Imaz MJ, Virto I, Bescansa P, Entrique A, Fernandez O, Karlen DL (2010) Soil quality indicator response to tillage and residue management on semi-arid Mediterranean cropland. Soil Tillage 107:17-25

44. Rezaei SA, Gilkes RJ, Andrews SS (2006) A minimum data set for assessing soil quality in rangelands. Geoderma 126:229-234

45. Basak N, Datta A, Biswas S, Mitran T, Mandal B (2016) Organic amendment influences soil quality in farmer's field under ricebased cropping systems in Indo-Gangetic Plains of India. Indian Soc Soil Sci 64:138-147

46. Smith OH, Petersen GW, Needelman BA (1999) Environmental Indicators of Agroecosystems. In: Sparks DL (ed) Advances in Agronomy. Academic Press Elsevier, Amsterdam, pp 75-97

47. Raiesi F, Kabiri V (2016) Identification of soil quality indicators for assessing the effect of different tillage practices through a soil quality index in a semi-arid environment. Ecol Ind 71:198-207

48. Chandel S, Hadda MS, Mahal AK (2018) Soil quality assessment through minimum data set under different land uses of submontane Punjab. Commun Soil Sci Plant Anal 49:658-674

49. Franchini JC, Crispino CC, Souza RA, Torres E, Hungria M (2007) Microbiological parameters as indicators of soil quality under various soil management and crop rotation systems in southern Brazil. Soil Tillage Res 92:18-29

50. Yao RJ, Yang JS, Zhang TJ, Gao P, Yu SP, Wang XP (2013) Shortterm effect of cultivation and crop rotation systems on soil quality indicators in a coastal newly reclaimed farming area. Soils Sediments 13:1335-1350

51. Filip Z (2002) International approach to assessing soil quality by ecologically-related biological parameters. Agr Ecosyst Environ 88:169-174

Publisher's Note Springer Nature remains neutral with regard to jurisdictional claims in published maps and institutional affiliations. 